\title{
Zugriffe auf das Ich
}

Psychoaktive Stoffe und Personenkonzepte in der Schweiz, 1945 bis 1980

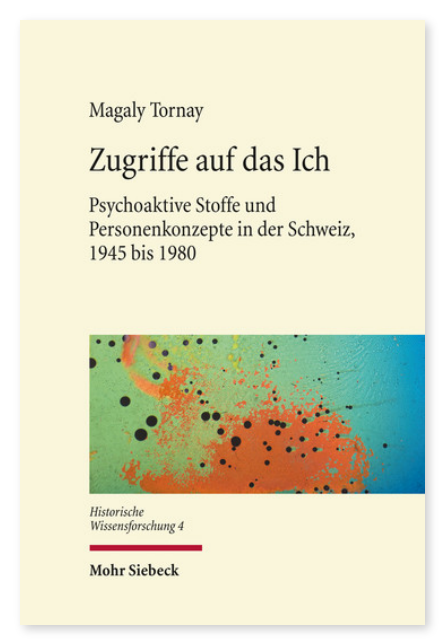

2016. XI, 286 Seiten. HWF 4

ISBN 978-3-16-154280-0

DOI 10.1628/978-3-16-154280-0

eBook PDF

ISBN 978-3-16-154279-4

Festeinband $64,00 €$
Wie beeinflussen psychoaktive Stoffe unser Bild von uns selbst? Verstehen wir seit der psychopharmakologischen Wende unser Inneres anders und wie hat sich dies auf unsere Vorstellungen von Gesundheit und Krankheit ausgewirkt? Entlang dieser Fragen zeichnet Magaly Tornay die Geschichte psychoaktiver Stoffe in der Schweiz seit dem Aufkommen des LSD nach. Das Spektrum der psychoaktiven Stoffe wurde in der Folge um Antidepressiva, Tranquilizer und Anregungsmittel erweitert. Der Mikroblick der Psychiater, die sich individuellen Patienten widmeten, wurde überlagert von einer Sichtweise, die psychische Störungen als chemisch veränderbar, experimentalisierbar und statistisch erfassbar begriff. Die Autorin zeigt auf, wie im Schnittfeld von psychiatrischen Kliniken, Pharmaunternehmen und Wissenschaft ein neues Objekt Kontur gewann: eine psychopharmakologische Grammatik, die den Diskurs über unser Inneres entscheidend mitprägte.

Magaly Tornay Studium der Geschichte, deutschen und lateinamerikanischen Literatur an der Universität Zürich; Dissertation an der Forschungsstelle für Sozial- und Wirtschaftsgeschichte; Forschungsaufenthalte in Berlin, London und Oxford; 2014 Promotion; wissenschaftliche Assistentin am Lehrstuhl Jakob Tanner; assoziiertes Mitglied am Zentrum Geschichte des Wissens, Universität und ETH Zürich.
Jetzt bestellen:

https://mohrsiebeck.com/buch/zugriffe-auf-das-ich-9783161542800?no_cache=1

order@mohrsiebeck.com

Telefon: +49 (0)7071-923-17

Telefax: +49 (0)7071-51104 